\title{
Educação Especial: Reflexões acerca da temática
}

\author{
Maria Zuleide de Lima Nogueira' ${ }^{\text {; Lireida Maria Albuquerque Bezerra }}{ }^{2}$
}

Resumo: Este artigo discute aspectos históricos da educação inclusiva. Conhecer contexto histórico da educação inclusiva ajuda na maneira de conviver com essa parcela da população. Este estudo se propões a realizar uma breve pesquisa bibliográfica sobre a história da Educação Especial no Brasil. Propõe, ainda, destacar a importância da comunidade escolar na vida da pessoa especial inclusa. O objetivo é, através de um resgate histórico, conhecer como se sucedeu a educação inclusiva e, como a pessoas com necessidades educativas especiais convivem hoje no espaço da sala de aula. Enfatizando a contribuição da família, da escola e dos professores como fundamentais para que a inclusão aconteça na prática. Conclui que a inclusão deve ter a participação de toda a sociedade, provocando mudanças não só físicas, mas também estrutural e curricular para que a pessoa inclusa tenha acesso a mesma educação daqueles que não tem necessidades especiais.

Palavras- chave: Inclusão, Necessidades educativas especiais, Educação inclusiva.

\section{Special Education: Reflections on the theme}

\begin{abstract}
This article discusses historical aspects of inclusive education. Knowing the historical context of inclusive education helps in the way of living with this part of the population. This study intends to carry out a brief bibliographical research on the history of Special Education in Brazil. It also proposes to highlight the importance of the school community in the life of the special person included. The objective is, through a historical rescue, to know how it happened to the inclusive education and, as people with special educational needs coexist today in the space of the classroom. Emphasizing the contribution of family, school and teachers as fundamental for inclusion to take place in practice. It concludes that inclusion must have the participation of the whole society, provoking not only physical changes, but also structural and curricular changes so that the included person has access to the same education of those who do not have special needs.
\end{abstract}

Keywords: Inclusion, Special educational needs, Inclusive education.

\section{Introdução}

A proposta deste artigo é apresentar um resgate histórico da educação inclusiva, principalmente no Brasil. Para entender como acontece nos dias atuais a inclusão na sala de aula. A princípio, destacar o papel das escolas especiais na origem da educação inclusiva, que pelo contrário do que se pensam elas foram fundamentais para os avanços da atualidade. Neste sentido, elas não podem ser consideradas como entraves da inclusão, pois a inclusão está também relacionada a laços culturais da sociedade.

\footnotetext{
${ }^{1}$ Programa de Mestrado em Educação da Anne Sullivan University. E-mail: zuleide.lima01 @ hotmail.com;

${ }^{2}$ Graduada em Geografia pela Faculdade de Filosofia do Crato. Especialização em Ciências na área de Concentração Geo ambiente. Mestre em Geografia pela Universidade Federal do Ceará. Atualmente é professora da Universidade Regional do Cariri, no Departamento de Geociências, no Curso de Geografia. E-mail: lireida.mabe@gmail.com.
} 
O surgimento de organizações a partir de 1930, em favor das pessoas com necessidades especiais, foi importante para solidificação de direitos da área, isto provocou a atenção do governo para que se implementassem ações em prol deste alunado. Adaptaram-se escolas junto a órgão de saúde e ampliou o ensino regular, isso, oportunizou que outras instituições especializadas particulares fossem surgindo, como instituto de reabilitação e como auxilio psicopedagógico.

$\mathrm{Na}$ atualidade tem sido considerável o avanço da inclusão, porém no Brasil ainda se costuma encontrar crianças fora da sala de aula, elas apresentam diverso motivo que levaram ela abandonarem a sala de aula. $\mathrm{O}$ que se pretende é desenvolver alternativa para que elas voltem, pois estudos comprovam que elas tem desejos de voltar a escola, para isto elas deverão ser alcançadas por projetos de ensino a jovens e adultos, uma vez que já atingiram a idade para tal modalidade.

É direito da criança ter acesso à educação de qualidade. A declaração Universal dos Direitos Humanos é muito clara quando esclarece que educação é direito de todas as crianças, independente de sua condição física ou social. Assim como os pais tem direito de ser consultado sobre a forma de educação que melhor se adapte ás necessidades, em comum acordo com as metas de seus filhos. Para Bastos (2003, p. 94) a: "distância existente no relacionamento entre os especialistas, a família e a escola impediam o desenvolvimento de um trabalho eficiente com o aluno".

Neste sentido, a família deve estar inserida no âmbito escolar para poder conviver com os avanços da criança, auxiliando no que for preciso. Embora se saiba que muitas dessas famílias de acordo como MEC (2004) convivem sozinhas e enfrentam diversas dificuldades que não ajudam na condução do desenvolvimento da criança, o que muitas das vezes contribui para que a criança já chegue à escola caracterizada pela exclusão familiar. Portanto, em comum acordo a Declaração de Salamanca (UNESCO, 1994), "a educação de crianças com necessidades educacionais especiais é uma tarefa a ser dividida entre pais e profissionais". De acordo com Santos (2003, p. 180) esclarece que:

[...] à mudança no eixo norteador das políticas e dos serviços educacionais e sociais, para a valorização das potencialidades existentes nos indivíduos com Necessidades Educacionais Especiais. Essa mudança consiste na descoberta, ampliação e aperfeiçoamento das potencialidades do sujeito, em detrimento as suas dificuldades, sejam elas de ordem cognitiva, psicomotora, afetiva ou social. 
Id on Line Revista Multidisciplinar e de Psicologia

Id on Line Multidisciplinary and Psycology Journal

UNESCO (1994), a escola deve assegurar que todas as crianças seja acolhidas em seu espaço, garantindo a elas o seu desenvolvimento em todos os sentidos, seja emocional ou cognitivos, independentemente de suas condições, lingüísticas, físicas, intelectuais, sociais, emocionais ou outras.

É preciso que a pessoa com NEEs possa desenvolver suas potencialidades no contexto do ensino regular, pois a educação especial deve ser concebida como uma área transversal dentro do sistema educacional, e não na segregação em instituições especializadas não permitindo uma abordagem que valorize as potencialidades da pessoa com NEEs. (MAGALHAES, 2003).

Quanto ao papel fundamental do educador que lida com pessoas com necessidades especiais na sala de aula, Ribeiro (2003) esclarece que o profissional da educação deve assumir a convicção de que todos são capazes de aprender e de que o pressuposto de sua aprendizagem é sua interação como o mundo - sua ação sobre os objetivos.

A motivação para pesquisar sobre a historia da educação inclusiva no Brasil surgiu do desejo de conhecer através de seu resgate histórico quais foram os primeiros passos dados em prol da pessoa com necessidades especiais, e assim entender como acontece nos dias atuais, perfazendo as principais conquistas legislativas e o surgimento de organizações filantrópicas em defesa da educação inclusiva no Brasil ao longo de seu tempo.

Deste modo, poder contribuir para novos estudos acadêmicos na área da educação inclusiva. Outrossim, é que este artigo venha favorecer novos avanços para a inclusão não só na sala de aula, mas no dia a dia da pessoa com deficiência.

Este artigo partiu da seguinte questão-problema: Como aconteceu e como acontece a educação inclusiva ao longo do tempo?

Partindo destes pressupostos, pontuaram-se os seguintes objetivos específicos: Identificar o processo histórico da educação inclusiva; Conhecer as instituições que colaboraram para a educação inclusiva no Brasil; Perceber a importância da psicanálise para compreender o comportamento da criança; identificar os avanços legislativos em prol da pessoa com NEEs no Brasil; Mostrar a importância da família junto a escola para o sucesso do desenvolvimento da criança com NEEs.

A metodologia que se adotou foi a de cunho puramente bibliográfica, portanto elaborada a partir de material já construído, deste modo, a pesquisa se fundamentou a partir de livros e 
Id on Line Revista Multidisciplinar e de Psicologia

Id on Line Multidisciplinary and Psycology Journal

artigos publicados na internet. Os autores que contribuíram com a base teórica foram: Mazzotta (2005), Bueno (1999); Mendes (2010), Jannuzzi (2004), dentre outros.

Conclui-se com o pensamento de que a educação inclusiva, ainda carece de atenção maior por parte dos governantes, e acima de tudo da sociedade como um todo.

\section{Educação Especial - Breve Resgate Histórico}

Vale frisar que conhecer o contexto da Educação Especial desde sua origem até a atualidade é importante para que se perceba que as escolas especiais são as principais responsáveis pelo desenvolvimento da inclusão, elas não podem ser consideradas como responsável da negação aos direitos de pessoas com necessidades educacionais especiais terem acesso à educação. Neste sentido é importante esclarecer que a inclusão ou a exclusão das pessoas com deficiência são inerentes também às questões culturais.

Antes disto, as pessoas que possuíssem problemas como a surdez, cegueira, deficiência intelectual, física e de algum outro órgão, ou ainda idosos não eram permitido que convivessem em ambientes com outros indivíduos que não possuíam qualquer problema exposto, desta maneira eram esquecidos ao abandono da sociedade.

Aranha (2005) aponta que foi a partir do fortalecimento do Cristianismo na Idade Média, que se fez surgir um novo segmento social. Com as conquistas de espaços feitas pelo clero houve o domínio da sociedade pela igreja, Com a religião em crescimento, a maneira de pensar do cristianismo se espalhou, com isto as pessoas com deficiência, por serem criaturas de Deus, não poderiam ser abandonadas a própria sorte ou exterminadas. Vale ressaltar que durante a inquisição pessoas que com deficiência eram consideradas como escolhida para expiação da culpa, como castigo de Deus, ou até mesmo consideradas possuída pelo demônio, desta feita poderiam ser exterminadas.

Sobre isto Mazzotta (2005) esclarece que até o século XVIII, o que se percebia em respeito da deficiência estava praticamente relacionado ao misticismo e ocultismo, porém não havia uma base científica para se definir a deficiência, não sendo, portanto, possível compreender os diferentes tipos de deficiência. Para o autor a falta de conhecimento sobre as deficiências, contribuiu para que os indivíduos com deficiência, por "serem diferentes", 
Id on Line Revista Multidisciplinar e de Psicologia

Id on Line Multidisciplinary and Psycology Journal

ficassem a margem da sociedade da época, totalmente ignoradas. A partir do advento da burguesia provocou também uma revolução no contexto da organização da vida econômica, política e social, assim como na maneira de trabalhar, passaram a se valorizar mais a produção, troca e comércio, proporcionando uma nova forma de ver o mundo.

Com o aumento e a valorização do trabalho e da produção, troca-se o olhar, antes do divino agora para o ser humano como centro das atenções. Verificando a mudança do olhar sobrenatural ao natural, a deficiência começa a ser vista de outra forma, ela passa a ser concebida pelos métodos originais da medicina como sendo um fenômeno natural e orgânico. A partir daí, elaborou-se paradigmas formais que se estabeleceram na sociedade com relação a esta maneira de enxergar a deficiência o que se tornou também na educação institucionalizada.

Nesse ínterim, pode-se dizer que a história da educação especial no Brasil começa a partir do século XIX. Na ocasião os serviços estabelecidos para tratar desse segmento da população, baseados nos princípios norte-americanos e europeus, chegaram ao Brasil por mãos de alguns brasileiros que se dispuseram a organizar e a tornar realidade às ações isoladas e particulares com o objetivo de atender a pessoas com deficiências físicas, mentais e sensoriais. Neste sentido o autor acrescenta que:

Essas iniciativas não estavam integradas às políticas públicas de educação e foi preciso o passar de um século, aproximadamente, para que a educação especial passasse a ser uma dos componentes de nosso sistema educacional. De fato, no início dos anos 60 é que essa modalidade de ensino foi instituída oficialmente, com a denominação de "educação dos excepcionais (MAZZOTTA, 2005, p.45).

Deste modo, pode-se assim dividir a história da educação de pessoas com deficiência no Brasil da seguinte forma:

- De 1854 a 1956 - marcado por iniciativas de caráter privado;

- De 1957 a 1993 - definido por ações oficiais de âmbito nacional;

- De 1993.... - caracterizado pelos movimentos em favor da inclusão escolar.

No primeiro período atenuou-se a atender os casos clínicos especializados, somando a eles a educação escolar. Vale ressaltar que foi nessa época que ocorreram a fundação das instituições mais tradicionais de assistência às pessoas com deficiências mental, físicas e sensoriais no país, tendo como base as atividades semelhante realizadas pelo Instituto dos Meninos Cegos, erguido na cidade do Rio de Janeiro, em fins de 1854. (MAMTOAN, s.d.). Como Romero (s.d.) acrescenta sobre a fundação deste Instituto, 
No Brasil, o primeiro marco da educação especial ocorreu no período imperial. Em 1854, Dom Pedro II, influenciado pelo ministro do Império Couto Ferraz, admirado com o trabalho do jovem cego José Álvares de Azevedo [...] Dr. Sigaud, criou o Imperial Instituto dos Meninos Cegos. Em 1891 a escola passou a se chamar Instituto Benjamin Constant - IBC. Em 1857, D. Pedro II também criou o Instituto Imperial dos Surdos-Mudos. A criação desta escola deve-se a Ernesto Hüet que veio da França para o Brasil com os planos de fundar uma escola para surdos-mudos. Em 1957 a escola passou a se chamar Instituto Nacional de Educação de Surdos - INES. Ainda no período imperial, em 1874, iniciou-se o tratamento de deficientes mentais no hospital psiquiátrico da Bahia (hoje hospital Juliano Moreira). (ROMERO, s.d.)

Para Bueno (1999), é no segundo paradigma que se tem os serviços que se distingue pela ideia principal, a integração. Com isto, as instituições não são mais locais de confinamento e, a esses locais são dadas outras funções, a de preparar o deficiente para o convívio em sociedade, possibilitando a ele o trabalho e a promoção de sua auto-suficiência. Pois para o autor a integração tinha como:

Pressuposto que o problema residia nas características das crianças excepcionais, na medida em que centrava toda sua argumentação na perspectiva de detecção mais precisa dessas características e no estabelecimento de critérios baseados nessa detecção para a incorporação ou não pelo ensino regular, expresso na afirmação - sempre que suas condições pessoais permitirem (BUENO, 1999, p 8)

Vale frisar que antes da fundação dessas instituições as pessoas que possuíam algum tipo de problema como: surdez, cegueira, deficiência intelectual, física e de algum órgão, assim como os idosos não tinha permissão para conviverem em ambientes com outros indivíduos que não possuíssem quaisquer problemas dos que foram citados.

\section{Educação Especial no Século XX}

Vale ressaltar que o panorama da educação, durante as duas primeiras décadas do século XX sofreu uma série de transformações político-sociais que resultaram em mudanças, uma vez que o país vivenciava uma fase de estruturação da república e emergiram discrepâncias regionais mais acentuadas. A estagnação econômica da sociedade brasileira permitiu a manutenção de um sistema dualista até a primeira guerra mundial, proporcionando os seus serviços a elite nacional e grande parcela da classe média. Nesta época as classes populares ainda não tinham acesso à escola (TTEIXEIRA, 1977) apud (MENDES, 2010, P. 95). 
De acordo com Aranha (2005), a população institucionalizada, custava cada vez mais caro, assim era melhor manter a população na improdutividade e na condição crônica de segregação, uma vez que a administração pública dos países que se adiantavam no estudo do sistema de atenção ao deficiente tornava-se interessante para ela, o discurso da autonomia e da produtividade do que o contrário.

Jannuzzi (2004), esclarece que a partir de 1930 é que surgem organizações populares em favor da pessoa com deficiência, a esfera governamental resolve a desencadear algumas ações visando a peculiaridade desse alunado, tais como: escolas junto a hospitais e ao ensino regular. Desta forma outras entidades filantrópicas especializadas continuaram sendo fundadas, assim como institutos psicopedagógigos e outros de reabilitação geralmente particular agregados ao atendimento em clínicas. "tudo isso no conjunto da educação geral na fase de incremento da industrialização do BR, comumente intitulada de substituição de importações, os espaços possíveis deixados pelas modificações capitalistas mundiais" (JANNUZZI, 2004 p.34).

Uma das associações que serviu como um aporte para as pessoas com deficiência no Brasil foi a APAE que é credenciada como parâmetro da organização da National Association for Retarded Children dos Estados Unidos da América. Ela surgiu em 1954 e se caracterizou como o movimento das Associações dos Pais e Amigos dos Excepcionais (APAE), favorecendo o crescimento do número de escolas especiais em todo o país. (ROGALSKI, 2010).

Um momento conturbado marcado pela crise da nova Pedagogia e pela articulação de tendência tecnicista, assumida pelo grupo militar e tecnocrata teve seu auge no período entre 1960 e 1968. A educação, a escola e o ensino foram vistos como investimentos no período de 1968/71, uma vez que a educação neste período passou a ser tratada como consequência do projeto de desenvolvimento econômico. Portanto, "A nova ideologia da eficácia da produtividade refletiu nas preocupações didáticas da época, reproduzindo o ensino da disciplina à dimensão técnica, afirmando a neutralidade científica dos métodos. (ROMANELLI, 2003 apud ROGALSKI, 2010). Muito se conquistou no âmbito da educação especial desde sua origem aos dias atuais, porém há de se ver que:

De longa data, a educação nacional vem mostrando o quanto necessita de mudanças para atender a todos os alunos, garantido o desenvolvimento escolar destes, e como nesse sentido, a vontade política para enfrentar um programa em favor das transformações de qualidade tem sido preferida pela opção por políticas que a um custo que não exija ampliação significativa da participação da educação na renda nacional e no orçamento público, privilegiam 
Id on Line Revista Multidisciplinar e de Psicologia

Id on Line Multidisciplinary and Psycology Journal

intervenções que tem sido compensatórias ou orientadoras para ações que possam mostrar números indicativos e maior acesso e permanência dos alunos no sistema escolar (FERREIRA \& FERREIRA, 2004, p.33).

Nesta assertiva, é que o movimento de integração social passou a ser a discutido, o que aconteceu no início da década de 70 , quando então se lutava para a inserção do deficiente na sociedade de uma forma geral. Quando se estuda o assunto a fundo se percebe que, de um modo geral, a prática de integração se acentuou a partir da década de 80, tomando como base o surgimento da luta nas reivindicações pelos direitos das pessoas com deficiência. Deste modo "Cabe salientar que a Educação Especial hoje, integrada ao sistema educacional identificou-se com suas dificuldades, objetivos e filosofia, que consiste em formar cidadãos conscientes e participativos". (SASSAKI, 2002 apud ROGALSKI, 2010).

É importante destacar a proposta da integração como um método que tem seu forte apelo contra a exclusão e a segregação de indivíduos com deficiência. Neste sentido, é feito todo um esforço para envolver e promover a aproximação entre o individuo deficiente e a escola normal, entre o individuo deficiente e a empresa onde está o trabalho para seu sustento, e assim por diante. Sobretudo com a tônica da responsabilidade assumida sobre esses indivíduos com deficiência, para que eles se prepararem para fazer parte da sociedade onde eles vivem a exemplo às escolas comuns, as empresa e etc. Por este ângulo, a sociedade é convocada a deixar para trás, o preconceito e passar a aceitar os indivíduos com deficiência, e assim conviverem em harmonia tendo à frente as garantias de seus direitos. (SASSAKI, 2005).

Para a autora é preciso que se molde aos requisitos básicos de respeito e garantia de direito, pois aos indivíduos com deficiência resta, muitas vezes, moldar-se a eles, como: requisitos dos serviços especiais separados, e passarem a conviver em classe especial, escola especial etc; além de terem que acompanhar os procedimentos tradicionais como: de trabalho, escolarização, convivência social etc; contornar os obstáculos existentes no meio físico (espaço urbano, edifícios, transportes etc); lidar com as atitudes discriminatórias da sociedade, resultantes de estereótipos, preconceitos e estigmas; desempenhar papéis sociais individuais (aluno, trabalhador, usuário, pai, mãe, consumidor etc.) com autonomia, mas, não necessariamente, com independência (SASSAKI, 2005, p. 21).

Para Aranha (2005) pressupõe-se de que a pessoa com deficiência tem direito à convivência não segregada assim como o acesso imediato e contínuo aos recursos a ela 
Id on Line Revista Multidisciplinar e de Psicologia

Id on Line Multidisciplinary and Psycology Journal

disponíveis como a qualquer outro cidadão. Porém, deve-se buscar o alcance desses direitos e identificar o que poderia garantir tais circunstâncias.

\section{Aspectos da Educação Inclusiva e Legislação Brasileira}

Embora se tenha discutido muito acerca do assunto, com a construção de projetos para acolher a pessoa com deficiência no Brasil na sala de aula, ainda se pode notar há crianças fora da escola. [...] são cerca de 2,7 milhões de crianças de 7 a 14 anos fora da escola, a partir daí se nota que o problema da exclusão ainda é grande no Brasil. Vale salientar que parte dessas crianças já esteve na escola, porém a abandonou. É importante destacar que parte dessa população pode ser trazida de volta à escola regular e a outra carece ser alcançada pelos programas de educação de jovens e adultos (BRASIL, 2011e).

Neste sentido, a inclusão tem desafios que fogem da concepção de quem os cuida, pois a idéia da inclusão tem sua base numa filosofia que reconhece e aceita a diversidade na vida em sociedade como um todo. Fica claro que, independentemente das peculiaridades de cada indivíduo no grupo social, é preciso garantir o acesso deles a todas as oportunidades da vida em sociedade. (MENDES, 2002 apud GLAT; FONTES; PLETSCH, 2006). Com base nesta concepção de garantias, que infelizmente há uma necessidade de mais ações nesse sentido, pois ainda, "são poucas as pesquisas, experiências e práticas educacionais, validadas cientificamente, que mostrem como fazer para incluir no cotidiano de uma classe regular alunos que apresentem diferentes tipos de necessidades educacionais especiais (GLAT; FERNANDES, 2005, p. 39).

O que se nota, a grosso modo, é que há uma facilidade da maneira como se ensina a esse aluno no espaço da sala de aula. É como se estes alunos não tivessem capacidade acadêmica para freqüentar as escolas comuns em detrimentos de suas deficiências físicas, intelectuais, sensoriais ou múltiplas, e faça com que se deixe implícito a existência de um sistema paralelo destinado exclusivamente aos alunos com deficiência no Brasil. (SASSAKI, 2005). Quanto ao material de apóio não se pode conceber que os serviços especializados se resumam às classes especiais, pois a rede de apoio dos recursos humanos, técnicos, tecnológicos e materiais 
Id on Line Revista Multidisciplinar e de Psicologia

Id on Line Multidisciplinary and Psycology Journal

oferecidos no sentido de apoiar e complementar as práticas do ensino comum deve ser a todo alunado. (PARANÁ, 2006).

No que se refere à AEE, vale ressaltar que, os alunos matriculados em classe comum de ensino regular público que tiverem matrícula concomitante no AEE, de acordo com Art. $8^{\circ}$ Serão contabilizados duplamente, no âmbito do FUNDEB, de acordo com o Decreto $\mathrm{N}^{\circ}$ 6.571/2008. O parágrafo único do mesmo artigo reza que:

a) matrícula em classe comum e em sala de recursos multifuncionais da mesma escola pública; b) matrícula em classe comum e em sala de recursos multifuncionais de outra escola pública; c) matrícula em classe comum e em centro de Atendimento Educacional Especializado de instituição de Educação Especial pública; d) matrícula em classe comum e em centro de Atendimento Educacional Especializado de instituições de Educação Especial comunitárias, confessionais ou filantrópicas sem fins lucrativos (BRASIL, 2010 apud LITWINCZUK, 2011, p.33)

Portanto, o financiamento da matrícula no AEE está subordinado à matrícula no ensino regular da rede pública, em consonância com registro no Censo Escolar/MEC/INEP do ano anterior, sendo contemplada nos casos supracitados. (BRASIL, 2010 apud LITWINCZUK, 2011).

O decreto supracitado preconiza que os profissionais educadores que devem lidar com o aluno com necessidades especiais em sala de aula devam ser considerados o seguinte:

\begin{abstract}
$\S 1^{\circ}$ São considerados professores capacitados para atuar em classes comuns com alunos que apresentam necessidades educacionais especiais aqueles que comprovem que, em sua formação, de nível médio ou superior, foram incluídos conteúdos sobre educação especial adequados ao desenvolvimento de competências e valores para: I - perceber as necessidades educacionais especiais dos alunos e valorizar a educação inclusiva; II - flexibilizar a ação pedagógica nas diferentes áreas de conhecimento de modo adequado às necessidades especiais de aprendizagem; III - avaliar continuamente a eficácia do processo educativo para o atendimento de necessidades educacionais especiais; IV - atuar em equipe, inclusive com professores especializados em educação especial. $\S 2^{\circ}$ São considerados professores especializados em educação especial aqueles que desenvolveram competências para identificar as necessidades educacionais especiais para definir, implementar, liderar e apoiar a implementação de estratégias de flexibilização, adaptação curricular, procedimentos didáticos pedagógicos e práticas alternativas, adequados aos atendimentos das mesmas, bem como trabalhar em equipe, assistindo o professor de classe comum nas práticas que são necessárias para promover a inclusão dos alunos com necessidades educacionais especiais (BRASIL, 2011 apud LITWINCZUK, 2011, p.46)
\end{abstract}

Neste sentido, Werneck (1997) apud (Rogalski1, 2010) destaca que tanto a constituição Brasileira quanto a Lei de Diretrizes e Bases da Educação, de 1996 são interpretadas por estudiosos como sendo incentivadoras da inclusão, uma vez que tanto uma quanto a outra define que o atendimento de alunos com deficiência deve ser especializado e de preferência na rede 
convencional de ensino. A Declaração dos direitos Humanos sinaliza que "É preciso repensar a formação de professores especializados, a fim de que estes sejam capazes de trabalhar em diferentes situações e possam assumir um papel - chave nos programas de necessidades educativas especiais”. (DECLARAÇÃO DE SALAMANCA p. 28).

\title{
A Inclusão sob o aspecto da Declaração de Salamanca
}

Deve-se entender pelo conceito de educação que todas as crianças devem ter acesso a educação de qualidade, uma vez que isto está proclamado na Declaração Universal dos Direitos Humanos, desta feita é que este importante documento retoma o norte de todas as pessoas com deficiência. Isto para garantir a elas o direito de expressar os seus anseios com relação à sua educação. Fica claro que "Os pais têm o direito inerente de ser consultados sobre a forma de educação que melhor se adapte às necessidades, circunstâncias e aspirações dos seus filhos". (DECLARAÇÃO DE SALAMANCA p. 5 - 6).

No que se relaciona a escola como um espaço de aprendizagem e novas possibilidades de ser cidadão a Declaração Universal dos Direitos Humanos, de 1948, afirma que:

\begin{abstract}
As escolas integradoras constituem um meio favorável à construção da igualdade de oportunidades da completa participação; mas, para ter êxito, requerem um esforço comum, não só dos professores e do pessoal restante da escola, mas também dos colegas, pais, famílias e voluntários. A reforma das instituiçõos sociais não só é uma tarefa técnica, mas também depende, antes de tudo, da convicção, do compromisso e da boa vontade de todos os indivíduos que integram a sociedade (2004, p. 14).
\end{abstract}

Portanto, as escolas devem acolher crianças com deficiência e crianças bem dotadas, crianças que vivem ao relento nas ruas e que vivem trabalhando; crianças de populações distantes ou nômades; independentemente de suas condições físicas, intelectuais, sociais, emocionais, linguísticas ou outras, assim como "as crianças de minorias linguísticas, étnicas ou culturais e crianças de outros grupos ou zonas desfavorecidas ou marginalizadas". (DECLARAÇÃO DE SALAMANCA p. 18).

Segundo Sassaki (2004), à diversidade do novo alunado quando se refere a necessidades especiais (não só as decorrentes de deficiência física, mental, visual, auditiva ou múltipla, como também aquelas resultantes de outras condições atípicas), deve ser acolhida pela escola muito bem estruturada de acordo com as necessidades destes educandos. A partir disto a escola pode 
Id on Line Revista Multidisciplinar e de Psicologia

Id on Line Multidisciplinary and Psycology Journal

se constituir inclusiva, caso contrario ela ainda não se tornou inclusiva de fato e de verdade. Para que isto ocorra a escola deve seguir os "termos de estilos e habilidades de aprendizagem dos alunos e em todos os outros requisitos do princípio da inclusão, conforme estabelecido no documento, 'A declaração de Salamanca e o Plano de Ação para Educação de Necessidades Especiais"”. (SASSAKI, 2004, p 2)

Mende (2002) esclarece que:

[...] inclusão estabelece que as diferenças humanas são normais, mas ao mesmo tempo reconhece que a escola atual tem provocado ou acentuado desigualdades associadas à existência de diferenças de origem pessoal, social, cultural e política, e é nesse sentido que ela prega a necessidade de reestruturação do sistema educacional para prover uma educação de qualidade a todas as crianças. ( p. 64)

Neste sentido pode-se afirma que a sociedade é mais humana se for mais inclusiva, no que concerne a educação escola inclusiva corresponde satisfatoriamente às exigências dos seus clientes, quanto os termos econômicos, "os recursos e equipamentos são distribuídos de forma mais sustentada e eqüitativa a toda a população, podendo garantir, por via de uma engenharia financeira mais adequada, melhor qualidade e mais abrangência social do sistema educativo". (MENDE, 2002, p. 64).

\section{Educação Inclusiva: Família, Escola e Professor}

Ao se referir a família como parte da comunidade escolar compreende-se que as famílias de crianças, jovens e adultos com necessidades especiais associadas ou não a deficiência. Convivem em uma situação bastante original, uma vez que a maioria delas encontra sozinha para conduzir as dificuldades que se apresentam nessas situações. "Os sentimentos de desamparo são muito freqüentes e não podem ser ignorados". (MEC, 2004, p.13). Nesta mesma assertiva, o MEC (2004), enfatiza que é preciso que os serviços de atendimento cheguem até elas, quando isto não acontece às famílias as próprias crianças já iniciam sua exclusão dentro de seu próprio lar, pois:

A família precisa contar com serviços de avaliação e de atendimento às crianças e adolescentes, de forma que possam freqüentar os espaços comuns da comunidade desde o início de suas vidas, juntamente com seus familiares. Quando a família não conta com esses 
Id on Line Revista Multidisciplinar e de Psicologia

Id on Line Multidisciplinary and Psycology Journal

serviços, tende a se fechar e a manter a criança em casa, iniciando um processo de segregação e de exclusão já no contexto familiar. (p. 13)

Neste sentido, as informações sobre os procedimentos de acesso a esses recursos devem ser facilitadas, assim como a maneira para que cada família chegue a eles. É preciso que haja mais informações sobre as necessidades especiais da criança, uma vez que isso tem "levado os pais a uma condição de dependência de um determinado serviço ou mesmo de profissionais. Dificilmente são orientados a analisar o conjunto de suas necessidades, a tomar decisões e exigir a qualidade de atendimento que desejam”. (MEC, 2004, p. 14)

Para o MEC (2004), garantir a participação de todos no compartilhar de sentimentos, na análise dos problemas é o que faz da família um coletivo e que carece, para seu pleno desenvolvimento, a manutenção destas conquistas, bem como no processo de tomada de decisões e responsabilidades. Para isto é preciso se investir nestas questões familiares e possibilitar o crescimento e desenvolvimento delas, a fim de que possam ter a qualidade de vida em todos os seus aspectos.

Ao se tratar da escola, Carvalho (1999) ementa que não é diferente o dia a dia na construção da aprendizagem, pois os estudos "tem demonstrado que a inclusão pode ser favorecida quando observam as seguintes providencias: preparação e dedicação dos professores; apoio especializado para os que necessitam; e a realização de adaptações curriculares e de acesso ao currículo, se pertinentes". (p.52). Para Batista (2006), deve haver uma reflexão acerca do que seja ensino e aprendizagem, para a autora "aprender é uma ação humana criativa, individual heterogênea e regulada pelo sujeito da aprendizagem, independente de sua condição intelectual ser mais ou menos privilegiada", ao passo que "ensinar é um ato coletivo, no qual o professor disponibiliza a todos alunos sem exceção um mesmo conhecimento" (p. 13). Deste modo, os conhecimentos, adquiridos pelo aluno, permitem a ele a capacidade de produzir saberes a partir das práticas escolares com condições de que esse aprender seja reconhecido e valorizado segundo suas possibilidades. Para que isto aconteça é preciso que o ensino escolar se caracterize por uma diversidade de atividades.

Batista (2006) apud Romero (s.d.) esclarece que o professor na visão da educação inclusiva, não é simplesmente aquele que leciona um "ensino diversificado" para alguns, é, sobretudo aquele que prepara atividades diversas para seu alunado, abrangendo não só aquele que tenha deficiência, mas o todo. Embora se trabalhe o mesmo conteúdo curricular. "As 
Id on Line Revista Multidisciplinar e de Psicologia

Id on Line Multidisciplinary and Psycology Journal

atividades não são graduadas, para atender a níveis diferentes de compreensão e estão disponíveis na sala de aula para que seus alunos as escolham livremente, de acordo com o interesse que têm por elas.” (p. 14).

\section{Considerações Finais}

Este artigo se propôs realizar um resgate histórico da educação inclusiva, principalmente no Brasil, consequentemente entender a educação inclusiva na atualidade. Procurou-se de forma breve conhecer como aconteceu o processo de inclusão a nível de mundo para depois adentrar no tema em questão.

Percebeu-se que a educação inclusiva passou por avanços significativos a partir das iniciativas de entidades filantrópicas, e que foram através de a da ação delas que o cenário da educação inclusiva se modificou. A ação dessas entidades fez com que o governo mudasse sua forma de trabalhar com este aluno, ampliando o ensino regular dentro das especificidades de cada pessoa com necessidades especiais.

Em detrimento da pesquisa se observou que nos dias atuais tem sido grande as conquistas da educação inclusiva, mas que ainda se precisa ir mais longe, uma vez que o estudo mostrou um número considerável de crianças com necessidades especiais que se encontram fora da sala de aula, ressaltando que um dia elas estiverem lá.

A criança tem direito a educação de qualidade, o que foi frisado pela declaração Universal dos Direitos Humanos, neste intelecto é preciso que os entraves pela educação inclusiva de fato e de verdade sejam sanados, ainda no lar da criança. Uma vez que o estudo mostrou que as famílias dessas crianças tem uma serie de problemas, e para resolvê-lo carece de uma ajuda externa. A escola é o segundo lugar onde a criança deve ser recebida, porem a educação dessas crianças deve ser partilhado com os pais. Os desafios dentro da sala de aula ainda são grandes, de um lado a criança que necessita de um acompanhamento adequado do outro a falta de profissionais exclusivos para orientá-las. A renovação da escola verdadeiramente inclusiva não deve ser só física tem que ser em todos so sentidos, pedagógicos, curriculares, emocionais e cognitivos. A aproximação da família da escola melhora os relacionamentos e produz um desenvolvimento satisfatório para a criança inclusa. 
Assim, o estudo mostrou que é necessário proporcionar a pessoa com NEEs as condições para que ela possa desenvolver suas potencialidades. A segregação em instituições na atualidade inibe a liberdades da pessoa com NEEs, não se pode negar a importância destas instituições para que se chegasse a esse patamar. Novas discussões e avanços da inclusão foram percebidos ao longo da pesquisa, porem é preciso que se ofereça a oportunidades da pessoa com necessidades especiais de interagir no âmbito com outros alunos para que se construa um cidadão, com as mesmas condições daqueles que não portam nenhuma necessidade especial.

Neste sentido, o estudo procurou responder aos seus objetivos específicos, e que foram correspondidos a contento, pois, percebeu-se que a educação inclusiva no Brasil se modificou ao longo de sua história. O que se tem hoje é resultado de lutas e conquistas feitas pela sociedade, sobretudo daqueles que se comoveram com a necessidade de se fazer mais pela pessoa co necessidade especiais. É preciso que todos, família onde é o lugar das relações primitiva da criança, a escola, e educadores produzam o seu trabalho em conjunto para que novas conquistas sejam ampliadas corroborando para o desenvolvimento e aprendizagem dessas crianças em sala de aula e na vida em sociedade.

\section{Referências}

ARANHA, Maria Salete Fábio. Inclusão Social e Municipalização. In: Eduardo José Manzini (Org.). Educação Especial: temas atuais. $1^{\text {a }}$ Edição. Marília: Unesp Marília Publicações, p. 1$10,2000$.

ARANHA, Salete Fábio (org.). Educação inclusiva : v. 4 : a família / coordenação geral SEESP/MEC ;. - Brasília : Ministério da Educação, Secretaria de Educação Especial, 2004. 17 p. Disponível em :<http://portal.mec.gov.br/seesp/arquivos/pdf/afamilia.pdf > Acesso em 14 de abril de 2016.

BATISTA, Cristina A. Mota. Educação inclusiva: atendimento educacional especializado para a deficiência mental. Brasília: MEC, SEESP, 2006.

BUENO, José Geraldo Silveira. Crianças com necessidades educativas especiais, política educacional e a formação de professores: generalistas ou especialistas? In: Revista Brasileira de Educação Especial,Piracicaba. Editora UNIMEP, v 3 nº 5, p 7 - 25, 1999.

CARVALHO, Rosita Elder. O Direito de Ter Direito. In: Salto para o futuro. Educação Especial: Tendências atuais/ Secretaria de Educação a Distância. Brasília: Ministério da 
Id on Line Revista Multidisciplinar e de Psicologia

Id on Line Multidisciplinary and Psycology Journal

Educação, SEEP, 1999.

DECLARAÇÃo DE SALAMANCA: sobre Princípios, Política e Práticas em Educação Especial. Espanha, 1994.

GLAT, R.; FERNANDES, E. M. Da educação segregada à educação inclusiva: uma breve reflexão sobre os paradigmas educacionais no contexto da educação especial brasileira. Inclusão - Revista da Educação Especial, Brasília, n.1, p. 35-39, out. 2005. Disponível em: <http://portal.mec.gov.br/seesp/arquivos/pdf/revistainclusao1.pdf>. Acesso: 7 de abril de 2016.

GLAT, R.; FONTES, R. S.; PLETSCH, M. D. Uma breve reflexão sobre o papel da Educação Especial frente ao processo de inclusão de pessoas com necessidades educacionais especiais em rede regular de ensino. Cadernos de Educação 6: Inclusão Social Desafios de uma Educação Cidadã. UNIGRANRIO Editora, Rio de Janeiro, p. 13-30, nov., 2006. Disponível em: <http://www.eduinclusivapesquerj.pro.br/livros_artigos/pdf/unigranrio.pdf> Acesso em 10 de abril de 2016.

JANUZZI, Gilberta de Martinho. A educação do deficiente no Brasil: dos primórdios ao início do século XXI. Campinas. Autores Associados, 2004. Coleção Educação Contemporânea.

LITWINCZUK, Lilian. Educação especial inclusiva no Brasil - trajetória histórica. Disponível em: <http://www.crc.uem.br/pedagogia/documentos/lilian_litwinczuk.pdf> Acesso em 14 de abril de 2016.

MANTOAN, M. T. E. et al. A interação de pessoas com deficiências. São Paulo: Menmon Editora, 1997.

MANTOAN, Maria Tereza Eglér. A Educação especial no Brasil - Da Exclusão à Inclusão Escolar. Disponível em: <http://www.lite.fe.unicamp.br/cursos/nt/ta1.3.htm> Acesso em: 14 de abril de 2016.

MAZZOTTA, Marcos J. S. Educação Especial no Brasil: história e políticas públicas. 5. ed. São Paulo: Cortez, 2005.

MENDES, E. G. Perspectivas para a construção da escola inclusiva no Brasil. In: PALHARES. 2002

MENDES, Enicéia Gonçalves. Breve histórico da educação especial no Brasil. Disponível em:

$<$ https://aprendeenlinea.udea.edu.co/revistas/index.php/revistaeyp/article/viewFile/9842/9041

$>$ Acesso em 14 de abril de 2016.

PARANÁ. Secretaria de Estado da Educação. Superintendência da Educação. Diretrizes Curriculares da Educação Especial para a Construção de Currículos Inclusivos. Curitiba, 2006.

ROGALSKI, Solange Menin. Histórico do surgimento da educação especial. Revista de 
Educação do IDEAU, v. 5, n. ${ }^{\circ}$ 12, jul-dez 2010. Disponível em: <http://www.ideau.com.br/upload/artigos/art_123.pdf> Acesso em: 15 de abril de 2016.

ROMANELLI, Otaiza de Oliveira. História da educação no Brasil. 28 ed. Petrópolis: Vozes, 2003.

ROMERO, Rosana Aparecida Silva. Educação Inclusiva: alugns marcos históricos que produziram educação atual. Disponível em: <http://www.pucpr.br/eventos/educere/educere2008/anais/pdf/447_408.pdf> Acesso em : 14 de abril de 2016.

SASSAKI, Romeu Kazumi. Inclusão: construindo uma sociedade para todos. 4 ed. Rio de Janeiro: WVA, 2002.

TELES, Margarida Maria. Declaração de Salamanca e Educação Inclusiva/2012. Disponível em: <http://geces.com.br/simposio/anais/anais-2012/Anais-077-087.pdf〉 Acesso em 14 de abril de 2016.

UNESCO (1994), UNESCO. Declaração de Salamanca e Linha de ação sobre necessidades educativas especiais.[Adotada pela Conferencia Mundial sobre Educação para Necessidades Especiais].Acesso e Qualidade, realizada em Salamanca, Espanha, entre 7 e 10 de junho de 1994.Genebra, UNESCO 1994.

Como citar este artigo (Formato ABNT):

NOGUEIRA, M.Z..L.; BEZERRA, L.M.A. Educação Especial: Reflexões acerca da temática. Id on Line Revista Multidisciplinar e de Psicologia, Janeiro de 2017, vol.10, n.33, p. 283-299. ISSN: 1981-1179.

Recebido: 06/12/2016

Aceito: 08/12/2016 